Para enlazar con este artículo / To link to this article:

http://dx.doi.org/10.14198/fem.2019.33.12

Para citar este artículo / To cite this article:

Goicoechea Gaona, M. ${ }^{a}$ Ángeles, Clavo Sebastián, M. ${ }^{a}$ José y Álvarez Terán, Remedios. «Feminismo y derechos para las mujeres homosexuales». En Feminismo/s, 33 (junio 2019): 297-322. DOI: 10.14198/fem.2019.33.12

\title{
FEMINISMO Y DERECHOS PARA LAS MUJERES HOMOSEXUALES ${ }^{1}$
}

\section{FEMINISM AND RIGHTS FOR HOMOSEXUAL WOMEN}

\author{
M. ángeles GoicoeCheA GaOnA \\ angeles.goicoechea@unirioja.es \\ http://orcid.org/0000-0002-3807-2443?lang=es \\ M. ${ }^{a}$ José Clavo Sebastián \\ maria-jose.clavo@aurea.unirioja.es \\ https://orcid.org/0000-0001-7788-5562?lang=es \\ Remedios ÁlVAREZ TERÁN \\ remediosat26@gmail.com \\ https://orcid.org/0000-0002-6195-9165 \\ Grupo de Investigación Igualdad y Género de la Universidad de La Rioja
}

\section{Resumen}

Este trabajo forma parte de una investigación que venimos desarrollando desde 2014 sobre las mujeres homosexuales en España, a partir de 41 entrevistas en profundidad. En este caso, se centra en las dificultades de inclusión asociadas a la homosexualidad y el grado de compromiso social y político que de ellas se derivan. Desde el marco teórico del feminismo, se combina la reflexión documental y bibliográfica sobre la diversidad afectiva, sexual y de género con los testimonios de las entrevistadas. La manera de manifestarse como mujer homosexual es muy plural, como es diversa la autodenominación. No todas se sienten deudoras del feminismo, y entre las que sí son

1. Este artículo ha sido subvencionado por el Instituto de Estudios Riojanos en la convocatoria 2017 de ayudas a la investigación.

Los contenidos de la revista se publican bajo una licencia de Creative Commons Reconocimiento 4.0 Internacional (CC BY 4.0)

Feminismo/s 33, junio 2019, pp. 297-322 


\title{
M. a Ángeles Goicoechea GaOna, M. ${ }^{a}$ José Clavo Sebastián y \\ REMEDIOS ÁlVAREZ TERÁN
}

Feminismo y derechos para las mujeres homosexuales

militantes también hay muchos matices. Las reivindicaciones personales se vuelven políticas gracias a los movimientos organizados, aunque muchas de sus necesidades permanecen con frecuencia ajenas a las agendas políticas.

Palabras clave: homosexualidad femenina, diversidad afectiva y sexual, feminismo.

\begin{abstract}
This work is part of a research that started and has been developing since 2014. We have interviewed 41 lesbians in Spain. This particular section examines the difficulties homosexuals have to overcome to be part of the community, and the social commitment that has arose from these circumstances. The testimonies of the interviewee have been analyzed from the theoretical framework of feminism, combined with the documentary and bibliographical reflection on affective, sexual and gender diversity. The self-expression and the self-designation of homosexual women is very plural. Not all of them feel indebted to feminism, and among those who are militants there are also many nuances. Personal demands become political thanks to organized movements, although many of their needs often remain outside political agendas.
\end{abstract}

Keywords: Female homosexuality, affective and sexual diversity, feminism.

Pues mi feminismo nace de mi lesbianismo básicamente. (Leticia)

\section{INTRODUCCIÓN}

Este trabajo forma parte de un estudio que venimos desarrollando desde 2014 sobre la realidad de las mujeres homosexuales en nuestro país. En una primera fase se constatan las dificultades con las que se encuentran en diversos espacios de su vida cotidiana; en la segunda, los procesos personales y sociales ante la maternidad; en la tercera, las dificultades de inclusión atribuibles a su orientación sexual y el grado de compromiso social y político que se deriva.

Presuponíamos que, como integrantes de un colectivo minoritario y transgresor, debían poseer una conciencia social y política reivindicativa que podría nutrirse del feminismo. Así que procedimos a identificar y analizar las dificultades que refieren por el hecho de ser mujeres homosexuales, y las fuerzas sociales que hay tras ellas. También analizamos la dificultad que muestran para autonombrarse, puesto que pone de manifiesto, en parte, su modo de vivirla.

Feminismo/s 33, junio 2019, pp. 297-322 
En el texto se identifican y describen muchos de los problemas que encuentran en su cotidianidad, y cómo la conciencia social se arraiga y se nutre del sentimiento de pertenencia a un colectivo con problemas de inclusión, aun si no se sienten capaces de nombrar la homosexualidad. Con sus voces exponen pensamientos y posiciones en relación con el feminismo, así como la reivindicación de los derechos que exigen para vivir en igualdad.

Comprobamos que, históricamente, una mayoría de ellas ha optado por el feminismo, por lo que nos ha interesado revisar las relaciones entre el lesbianismo y el feminismo en España, y lo hemos hecho teniendo muy presente que el movimiento lesbiano ha sido un sujeto político que ha aportado al feminismo importantes debates y vías de análisis que han ampliado las preocupaciones y luchas.

Finalmente, analizamos las respuestas a la pregunta inicial, formulada en la entrevista, sobre si el feminismo ha sido o no un elemento configurador de sus reivindicaciones de igualdad como mujeres lesbianas en una sociedad heterosexual, para comprobar, así, su grado de posicionamiento, y cuáles son, también, las reivindicaciones expresadas de forma espontánea, más allá de los programas de los grupos organizados.

\section{METODOLOGÍA}

Partimos del marco teórico del feminismo, por ello se combina la reflexión documental y bibliográfica sobre la diversidad afectiva, sexual y de género con los testimonios de mujeres que han compartido su tiempo y vivencias.

Las características de la muestra son muy diversas. Respecto a la edad de las entrevistadas, oscila entre 21 y 69 años, situándose la mayoría entre los 30 y 50. Proceden 39 de España, una es norteamericana y una mexicana. En cuanto a la formación, 23 son universitarias, 13 tienen estudios medios y cinco básicos. Siete residen en pueblos, y 34 en ciudades. Han militado o militan en un colectivo LGTB2 11 de ellas. Su nexo común es sentirse atraídas por otras mujeres.

2. Las siglas LGTB (Lesbianas, Gais, Transexuales y Bisexuales) son las adoptadas en el texto para referirse a toda la diversidad del género.

Feminismo/s 33, junio 2019, pp. 297-322 
El número de entrevistadas en total es de 41, todas ellas residentes en España, pero en distintas comunidades autónomas: La Rioja, País Vasco, Navarra, Aragón, Madrid y Cataluña.

Una sola investigadora realiza el trabajo de campo siguiendo el mismo patrón de preguntas abiertas. Si bien en la primera fase son más generales y abordan varios temas, en la segunda se centran en la maternidad y en la tercera profundizan en la conciencia social. En todos los casos hay cuestiones comunes sobre la toma de conciencia identitaria y las reivindicaciones, las diferencias entre mujeres y hombres y la militancia en los colectivos LGTB.

Las entrevistas, con una duración cercana a las dos horas, se transcriben posteriormente. Con el fin de proteger y respetar la privacidad, los nombres asignados son ficticios.

\section{LESBIANAS EN EL FEMINISMO}

En este epígrafe se analizan las relaciones entre el activismo lesbiano y el feminismo en España desde la transición, siendo muy valiosas las aportaciones de Gimeno, Osborne y Trujillo.

Muchas mujeres homosexuales sienten pertenecer a un grupo discriminado y buscan estrategias de denuncia a través del activismo político.

Señala Trujillo que existen lagunas insalvables para conocer el activismo lesbiano en España. No hay análisis sobre estas organizaciones ni sobre sus activistas, y cuando militan en otras organizaciones afines tampoco están reflejadas o no dejan su huella ni en las organizaciones feministas ni en las asociaciones LGTB. Las protagonistas son mencionadas de pasada en párrafos sueltos, «[...] cuando aparecen, o en notas al pie de página en las que se puede leer el por qué no se las incluye: porque es muy difícil localizar a mujeres lesbianas...» (Trujillo 33-34). O sea, no hay fuentes o están ocultas, dispersas, desorganizadas, no hay un archivo único donde encontrarlas (Trujillo 31).

Las autoras consultadas (Gimeno, Trujillo y Villar) coinciden en que el activismo lesbiano se ha movido históricamente entre dos ejes: el feminismo y los movimientos de defensa de las minorías sexuales (Trujillo 21). Para Gimeno (28), el feminismo vendría a paliar los daños que la heterosexualidad genera a todas las mujeres, dejando claro que el cuerpo es de cada una, de ahí el derecho a elegir si ser madres o no y cuándo, la penalización del 
maltrato, la discriminación positiva, etc. La ideología ha contribuido a combatir problemas de salud física y mental, económicos, políticos y personales que ocasiona el patriarcado. Mientras que la integración en los colectivos gais les permite reivindicaciones más específicas, pero apenas les ha dado visibilidad y presencia pública (Villar).

La ausencia de una narrativa genealógica tiene consecuencias en la construcción de la identidad, ya que significa crecer y desarrollarse sin tener referentes positivos en los que reflejarse. Sin historia, sin memoria, no es posible nombrarnos, por eso son tan importantes los esfuerzos por investigar, transmitir y visibilizar la trayectoria de estas mujeres.

Si seguimos a Trujillo, el activismo se puede agrupar en torno a tres momentos que vendrían a coincidir con las tres décadas finales del siglo pasado. En los setenta, el marco ideológico de las activistas lesbianas, fraguado en la izquierda antifranquista, se superpone con el feminismo, se consideran ante todo mujeres; en los ochenta, «la dimensión sexual colapsa dentro de la dimensión de género, y el feminismo pasa a ocupar un segundo plano» (Trujillo 234); y, finalmente, en los noventa, el ideario feminista queda atrás, se enfatiza la dimensión sexual (Trujillo 194-195), se imponen otros discursos propios que hacen hincapié en la visibilidad, el orgullo, la cultura y la comunidad LGTB (Trujillo 234-235).

Dice Pineda (31-61) que las lesbianas más o menos organizadas conviven con el Movimiento Feminista (MF) en España desde sus inicios en 1975. En esos primeros años el feminismo introduce las transformaciones ideológicas sobre la igualdad sexual que ya se encontraban plenamente vigentes en otros países europeos, y que suponen un importantísimo cambio de mentalidad social. Se pone de relieve el sometimiento sexual femenino, se defiende la libertad sexual, la separación entre sexo y reproducción, se exige la legalización de los anticonceptivos, la aprobación del divorcio, la legalización del aborto y el derecho al propio cuerpo.

Simultáneamente, en EEUU Rich defiende el «continuum lesbiano» como opción política femenina frente al poder del patriarcado. Un pensamiento definitivamente influyente en los feminismos de la segunda ola y que en España es recogido, sobre todo, por Victoria Sau, importante referente del feminismo español, la cual, con una tesis similar, señala que la específica orientación 
sexual lesbiana representa una alternativa que subvierte el sistema patriarcal de opresión femenina y, como tal, puede representar una opción política válida para todas las mujeres. Esta propuesta antipatriarcal del pensamiento feminista lesbiano tuvo un amplio eco entre las filas feministas. Sin embargo, las mujeres homosexuales dentro del movimiento pronto reivindicaron que lo esencial del lesbianismo es su orientación sexual, que no debe ser absorbida ni confundida con la idea de ser una opción política. Así lo expresa una entrevistada: «Y además yo creo que en algún libro lo leí, como que una mujer ame a otra mujer es un acto en sí de rebeldía contra el heteropatriarcado. Entonces pues eso no gusta». (Gala)

Aunque el feminismo socava los cimientos de la ideología patriarcal, el patrón sexual mayoritario entre las feministas sigue siendo la heterosexualidad, las lesbianas encuentran que sus necesidades y reivindicaciones no siempre coinciden. «Si el feminismo cuestionó lo masculino y lo femenino, y para ello el concepto central fue el de género, desde el lesbianismo se cuestionó la heterosexualidad/homosexualidad y por ello se puede decir que el centro del pensamiento lesbiano es la sexualidad» (Osborne 92). Estos conflictos resultan enriquecedores para el feminismo porque el situar en el centro del debate el problema de la sexualidad abrió nuevos caminos a la investigación y nuevos análisis acerca de la opresión patriarcal, identificada ahora con la prescripción normativa y simbólica de la heterosexualidad a la que se va considerando desde una óptica constructivista (Rubin 117).

Coincidiendo con la década de los ochenta, podemos hablar de un segundo periodo en el que las lesbianas crean asociaciones propias dentro del feminismo o mixtas con colectivos gais. Se trata de reivindicar sus derechos desde esa específica perspectiva. Entre las asociaciones más influyentes están las lesbianas del Frente de Liberación Homosexual de Castilla (FLHOC), las mujeres homosexuales como ESAM (Euskadi) y GLAL (Barcelona) y, sobre todo, el Colectivo de Feministas Lesbianas de Madrid (CFLM) agrupadas en la Coordinadora de Organizaciones Feministas del Estado Español.

Esta última (CFLM), que nace en 1981, es quizás la más activa e influyente para el colectivo, ya que muchas de ellas mismas eran lesbianas. Pretenden tres objetivos: 
1. Que se incluya en la agenda feminista la defensa del lesbianismo como una opción sexual tan legítima, normal y natural como la heterosexual.

2. Vivir y ayudarse a vivir con orgullo la común sexualidad lésbica.

3. La difusión de sus ideas.

Dice Pineda: «Estábamos firmemente persuadidas de que con ello ganaríamos todas las mujeres y de que el movimiento feminista sería más liberador de lo que ya quería o pretendía ser» (37-38). Son años de una gran actividad, fundan la revista Nosotras, que nos queremos tanto, con gran calado y difusión. Pero la invisibilidad sigue siendo una constante.

En 1987, con motivo de la detención y agresión a dos lesbianas por parte de la Policía Nacional por besarse en público en la Puerta del Sol, la CFLM convoca una gran besada reivindicativa. La respuesta de las feministas, tanto heterosexuales como lesbianas, es masiva y los medios de comunicación pueden difundir el espectáculo.

Al final de la década emerge con fuerza el debate sobre la pornografía promovido por el pensamiento lesbiano y del interés del feminismo norteamericano. Este interés suscitó una intensa polémica, aun hoy irresuelta, entre feministas abolicionistas y las que consideraban el porno como expresión de la libertad sexual, del derecho al propio cuerpo y al placer, sin las ataduras convencionales que han vinculado las prácticas sexuales a la procreación, el matrimonio o el amor romántico. «Las discusiones sobre el lesbianismo de uno u otro signo tuvieron la virtud de poner en el centro del debate la figura de la sexualidad y el cuestionamiento de la heterosexualidad como institución» (Osborne 94).

El tercer momento, que perdura hasta hoy, se inicia en los noventa. Se articulan otros discursos como los propios de gais, lesbianas y queer, que hacen hincapié en la visibilidad, el orgullo, la cultura y la comunidad LGTB (Trujillo 234-235).

La identidad homosexual de la que se han dotado los colectivos LGTB descansa en un esencialismo contra el que han surgido posiciones críticas. La teoría queer señala que las identidades fijas no son reales y que ese esencialismo impide la transformación social. En España, sin embargo, esta corriente no ha tenido acogida, aunque sí ha estado presente en el debate teórico. Desde 
esta perspectiva, se cuestiona el sujeto político y se considera que la identidad es una construcción social y un factor de discriminación que sitúa en sus márgenes a quienes no encajan con esas identidades construidas. En realidad, «[...] no solo giran en torno a la existencia de otras identidades sexuales, sino también cómo grupos de otras razas, clases sociales, nacionalidades, estatus legales, etc., viven y gestionan deseos y placeres sexuales distintos a la norma heterosexual» (Trujillo 212). Se promueve una actitud de resistencia a las normas y se critican las posturas asimilacionistas del lesbianismo, y la homosexualidad en general, que buscan «normalizar» su situación. Así, consideran que es una deserción la lucha y consecución de la ley del matrimonio homosexual por lo que significa de sumisión al orden social establecido:

Bueno al final yo creo que también el matrimonio homosexual en cierta manera - un poco nosotras la crítica que hacemos que no queremos tener, o sea, ya no es que deseemos a una mujer o deseemos a un hombre o deseemos en general-, sino con lo que queremos romper es con relaciones heteronormativas. Entonces un poco con el heteropatriarcado, romper con la heterosexualidad obligatoria, romper con el sistema patriarcal, romper un poco el sistema, en general. (Idoya)

En resumen, aunque hay muy poca información, sí se puede afirmar que el activismo lesbiano en España, desde la transición hasta nuestros días, se desenvuelve en espacios políticos feministas y que los problemas específicos que plantea la homosexualidad femenina han ampliado los márgenes ideológicos del feminismo, aunque en ocasiones la convivencia no haya sido fácil (Gimeno 193). Actualmente el colectivo LGTB tiene una entidad y un potencial transformador social y político muy relevantes y ha conseguido importantes cambios sociales, políticos y legislativos. Sin embargo, permanece de espaldas al feminismo: «[...] ni la agenda política del movimiento, ni las reivindicaciones básicas, ni la política que se hace, ni el discurso se han impregnado realmente del feminismo lesbiano y esta integración se ha hecho a costa de importantes renuncias» (Gimeno 199).

Por otro lado, muchas lesbianas son conscientes de que la homofobia está en relación muy estrecha con el patriarcado, cuya desactivación es el objetivo de todos los feminismos: «[...] ves que sigue siendo una sociedad machista [...] Sí, porque es que se trata de igualdad y se trata de que el macho alfa no 


\section{M. a Ángeles Goicoechea GaOna, M. ${ }^{a}$ José Clavo Sebastián y \\ REMEDIOS ÁlVAREZ TERÁN}

Feminismo y derechos para las mujeres homosexuales

se sienta humillado, porque hay una mujer que prefiere a otra mujer en vez de a él». (Herminia)

Otra entrevistada verbaliza esta relación y reconoce que el feminismo sigue siendo su escudo, porque su marginación es doble, por mujer y por lesbiana:

[...] pero ante el mismo puesto de trabajo o ante la misma vacante tengo que tener la igualdad de oportunidades y los mismos derechos. No puede pesar más la contratación de un hombre, porque no se va a quedar embarazada que contratarme a mí. A mí mi jefe cuando me contrató, yo entré con 20 años en la empresa donde estoy trabajando todavía, y dijo: « $i$ Te vas a quedar embarazada?». Y me preguntó: «iY tus padres te dejan viajar con esta edad?». O sea, yo estoy segura que a mis compañeros no les preguntó eso, a mis compañeros hombres. (Elisa)

Tesis defendida por hooks: «Hacer frente a la homofobia siempre será una dimensión del movimiento feminista» (127). Pero no todas las lesbianas comparten esta opinión. Vamos a verlo en el siguiente apartado.

\section{4. ¿LESBIANAS, BOLLERAS, HOMOSEXUALES, GAIS?}

Las mujeres lesbianas muestran su homosexualidad de forma desigual (Goicoechea, Fernández, Clavo y Álvarez). A partir de los datos del trabajo de campo, apreciamos que se posicionan en tramos de una línea continua, que simplificamos en tres subgrupos:

1. Declaran abiertamente la homosexualidad el 80,4\%. Las que menos problemas tienen son las que residen lejos de donde han nacido y de sus familias.

2. El 14,6\% mantiene su orientación afectiva y sexual en el ámbito privado de sus relaciones más cercanas. Incluimos a aquellas que dicen no sentir la necesidad de hacer pública su intimidad y a quienes, al tener descendencia, se ven 'obligadas' a mostrarse públicamente como pareja de madres.

3. Un 4,8\% solo muestra su orientación sexual entre personas muy cercanas que guardan su secreto. Estas llevan una doble vida. Cada vez son menos, pero supone un esfuerzo añadido a las dificultades cotidianas y un sufrimiento innecesario. Así lo expresa Leticia, aunque 
ella es visible: «[...] los armarios perjudican la salud mental [...] Una doble vida te crea muchos trastornos, muchas complicaciones psicológicas, yo creo». (Leticia)

El reducido tamaño de la Comunidad riojana, su configuración como territorio rural, y por lo tanto más conservador, no animan a 'salir del armario'. También es definitiva la variable edad, a mayor edad, mayor ocultación. Esto es debido a que la sociedad española va cambiando su mentalidad y se vuelve más inclusiva (CIS 2854). Aunque, como hemos señalado, siempre queda un sustrato homofóbico residual: «Yo de estudiante ni sabía lo que era ser lesbiana y ahora de profesora escucho a mis alumnas diciendo que son lesbianas con absoluta naturalidad». (Herminia)

A pesar de que los datos revelan que todavía el $85 \%$ de las entrevistadas, las de mayor edad y las que residen en ciudades pequeñas, muestran poca autoconfianza o poca naturalidad, se aprecia un cambio positivo:

[...] no sé si se ha avanzado, no creo que se haya avanzado lo suficiente, pero yo creo que cada vez, bueno, pues la gente está más empoderada y vive su orientación sexual como quiere. Yo lo veo en la calle, veo cada vez a más parejas homos agarradas de la mano, dándose besos, unas muestras de afecto que yo creo que antes en público no se hacían tanto. (Idoya)

En la transformación personal y colectiva también influye la pertenencia o no a movimientos sociales y políticos, especialmente feministas y LGTB. Por esta razón, aquellas mujeres vinculadas a asociaciones se encuentran más empoderadas para manifestar su orientación afectiva. Y porque, como afirma Idoya, «el discurso feminista ya va calando».

El 24,4\% de entrevistadas ha transitado desde la heterosexualidad hasta la homosexualidad, pues mantuvo relaciones íntimas con hombres en el pasado. Esas primeras experiencias generan en algunas la negación de su lesbianismo, justificando su orientación actual desde el amor hacia la persona, independientemente del género, para afirmar posteriormente que ya no tendrían relaciones con hombres. Solo un 13,33\% atestigua que la tendría.

Las dificultades para nombrarse muestran que no hay adecuación entre experiencia y lenguaje en el proceso de constitución de la subjetividad lesbiana. La explicación podría encontrase, en parte, en que los conceptos que tratan de designar esta experiencia pertenecen a los códigos lingüísticos que 


\section{M. a Ángeles Goicoechea GaOna, M. ${ }^{a}$ José Clavo Sebastián y \\ REMEDIOS ÁlVAREZ TERÁN}

Feminismo y derechos para las mujeres homosexuales

se originan en la cultura hegemónica heterosexual. Falta una representación cuyo nombre proceda del lugar adecuado: la experiencia subjetiva de las mujeres homosexuales, lo que pone de manifiesto hasta qué punto alcanza su invisibilidad. No obstante, sintetizando sus autopercepciones, se encuentran estas denominaciones:

- Lesbiana es el nombre que acepta la mayoría de las entrevistadas (75,6\%): «yo soy una señora lesbiana» (Herminia).

- Bollera se utiliza en diferentes contextos y con connotaciones muy distintas: reivindicativas para el $2,4 \%$ y coloquiales para el $4,87 \%$ :

[...] nosotras en todos los años que hemos estado activas como grupo bollero, más que lesbianas, nosotras nos hemos definido como bolleras. Nos parecía un término más subversivo, políticamente más fuerte que lesbiana, aunque en un momento sí que nos planteamos que igual lesbiana incluso era más potente que bollero, porque bollero pues es un poco queer. (Idoya)

[...] utilizo mucho 'bollera', porque en círculos de amistad y eso me sale mucho más, es como más coloquial. (Paula)

- Homosexual. Mercedes lo utiliza en la entrevista e Irene, que lo alterna con lesbiana.

- Pansexual. Encontramos a dos mujeres que se definen como bisexuales. Una, que al enamorarse de un hombre ha tenido que cuestionar su propia orientación:

Yo, me gusta más definirme como bisexual, pero sí que es verdad que como está creando ese término un poco de controversia en el mundo LGTBI, que si puedes ser transfo, ese... bueno, bisexual estás diciendo que tienes atracción hacia dos sexos o dos géneros, ¿no? Y claro, desde el movimiento LGTBIQ, sobre todo el movimiento queer y tal, que se defiende que no son dos sexos, sino que hay más. Entonces ¿me podría llegar a definir como pansexual? Pues sí, porque me parece un término igual que si quieres más inclusivo. $[\ldots]$ yo no tengo dudas ahora mismo de que me pudiese gustar, por ejemplo, una persona transexual, con un género no binario, o sea, creo que me pueden gustar, y de hecho pues cuando he conocido a gente, $[\ldots$ en] otros ambientes más abiertos y sí que te sientes esa atracción por gente que se define como no binaria o que son trans.

Feminismo/s 33, junio 2019, pp. 297-322 
Entonces ¿podría decir que soy pansexual? Sí. No lo digo por eso, porque no se usa en mi entorno. (Gala)

- Gay es como se define una entrevistada a la que le disgusta el término lesbiana:

[...] yo me considero gay, porque internacionalmente somos gais, las lesbianas son gais. (Remedios)

- Sin nombre, es decir, dos mujeres que no nombran su homosexualidad:

A mí no... ni me molesta ni me... no. Es verdad que hay que llamarlo de alguna manera. [E: ¿Utilizas la palabra lesbiana?] En mi día a día, no $[. .$.$] «Soy lesbiana». No... no lo digo (Sonia)$

¿O la quieren camuflar?: «Lesbiana, es que lesbiana a veces tiene una connotación negativa [...] Me gusta más mujer que... Lo otro es como un añadido». (Belinda)

No existe una única manera de nombrarse. Cada cual escoge de entre las aceptadas y, en ocasiones, transitan en este continuum del deseo, el amor y la sexualidad humana.

\section{5. ¿ES POSIBLE PARA UNA MUJER LESBIANA VIVIR LIBREMENTE SU HOMOSEXUALIDAD?}

Tradicionalmente, la heterosexualidad es la orientación sexual determinada por la biología, la natural para la especie. Así que cualquier otra variante viene siendo considerada una enfermedad o una desviación. El código simbólico que prescribe y define las pautas de la sexualidad aceptada se denomina «heteronormativo», y considera transgresoras aquellas prácticas u orientaciones sexuales que no respetan esa norma preestablecida.

De acuerdo con los análisis del pensamiento feminista (Rich), la heterosexualidad obligatoria no es simplemente la expresión de unas pautas culturales sobre la corrección o incorrección de la actividad y orientación sexuales, sino que permite subordinar a las mujeres. Mediante la identificación de sexo y género, se modula la orientación sexual y emocional de la mitad de la humanidad, de modo que cumpla con las funciones del matrimonio, la maternidad, la crianza de la prole y las tareas domésticas del espacio privado, en consonancia con la división sexual del trabajo. Para Josune no hay lugar a dudas:

Feminismo/s 33, junio 2019, pp. 297-322 
[...] esas leyes lo que hacen es perpetuar la heteronormatividad [...] desde la ley del matrimonio, me da la sensación que hay más plumofobia [...] Eso de querer ser normal por parte de los gais y lesbianas. Luego el Estado claro que te deja casarte para que sigas construyendo microfamilias y compres hipotecas... (Josune)

Las mujeres homosexuales contravienen los roles convencionales de la feminidad y generan así opciones vitales que transcurren por cauces diferentes a los que la sociedad les tenía marcados. La homosexualidad femenina es vista como un desafío a las pautas de la sexualidad normativa:

[...] cuestionan los valores que conforman las sociedades tradicionales: el matrimonio, la familia, la dependencia de la mujer respecto del hombre y los papeles masculinos y femeninos. El ser lesbiana atenta contra estos valores ya que significa que el sexo también es placer y no sólo reproducción (Villar y Mujika 4).

Las consecuencias para ellas son la represión, la invisibilización, la exclusión y la estigmatización. La sociedad patriarcal utiliza las fuerzas y recursos que posee para sancionarlas, porque hacen peligrar el sistema. Estos recursos son muy poderosos y, aunque no se utilizan con la misma intensidad en todas las culturas, lo cierto es que, de una forma u otra, las leyes, la educación, las instituciones religiosas, las ideologías, el ámbito laboral, las costumbres e incluso la ciencia las discriminan en la mayor parte de las sociedades. La acción conjunta de estos mecanismos es la creación y vigencia de mitos y estereotipos que provocan el rechazo social.

Nuestra sociedad no está libre de estos prejuicios, cuando el Centro de Investigaciones Sociológicas pregunta por las actitudes hacia la homosexualidad, encuentra diferentes porcentajes de personas que dicen manifestarles su rechazo en forma de comentarios negativos, rumores, burlas, imitaciones, amenazas, empujones y palizas; que afirma invisibilizarlas, ignorarlas o impedirles participar, aislarlas en una palabra (CIS 2854).

Nerea, entrevistada de 20 años, refiere haber sufrido bullying en el colegio. Le resta importancia, porque piensa que le ha permitido madurar, y no cree que sea homofobia, sin embargo, lo es: « [...] empieza siendo una broma, pero luego, al final, un día te acaban haciendo un corrito en el recreo o te quedas sola. Y luego ya, de repente, se enteran de que lo más seguro es que me gustan las chicas y me chistan por la calle o cosas así». (Nerea) 
Platero y Fernández (9-10) distinguen tres niveles de violencia soportada por los colectivos homosexuales:

- Individual: ejercida por individuos o grupos particulares. Es la más frecuente según las entrevistadas:

[...] de gente más mayor [...] que no deberían hacerlo, pero puede llegar a ser más entendible porque es otra generación, que sí pues que te miran o que te dicen cualquier cosa, pero bueno. [E: ¿Y te dicen cosas ofensivas?] Sí, alguna vez me han dicho que no, que deje de montar el espectáculo, que eso no es para hacerlo en la calle, pero cuando estaba dando un beso con mi novia o cualquier cosa. Pero bueno. (Felisa)

- Gubernamental: ejercida por instituciones públicas y varía de un estado a otro. En España se muestra, por ejemplo, en la legislación, en la ausencia de representación suficiente de personas no heterosexuales en las instituciones y en el ejercicio ordinario de la actividad política.

- Sociocultural: es el nivel de violencia más amplio e incluye a toda la sociedad. Amparado por el sistema simbólico hegemónico heteronormativo, el patriarcado incluye todas las prácticas de violencia de mayor o menor intensidad antes relatadas.

Ahora ya últimamente se está abriendo más a parejas de chicas, pero al final como vivimos en una sociedad heteropatriarcal lo que domina es la figura masculina. Y aparte te venden como una figura de homosexuales blancos, ricos, guapos, no se abre a todo lo que puede ser el espectro de diversidad, sino a un tipo bastante resumido. (Felisa)

La interseccionalidad de las mujeres lesbianas, pobres y negras no es el objeto de esta investigación, aunque aparece en testimonios de aquellas entrevistadas vinculadas a movimientos feministas. Este aspecto es abordado por escritoras norteamericanas como: hooks (2017), Anzaldúa (2007) y Fraser y Honneth (2006).

Todo este entramado hostil contra la asunción de una identidad no normativa, y su no aceptación de los roles de mujeres establecidos, tienen 


\section{M. ángeles Goicoechea Gaona, M. ${ }^{a}$ José Clavo Sebastián y \\ REMEDIOS ÁlVAREZ TERÁN}

Feminismo y derechos para las mujeres homosexuales

consecuencias negativas en su desarrollo psicológico y en sus procesos internos de enfrentamiento con el descubrimiento de su homosexualidad:

Al principio me sentí mal -ya te lo estoy diciendo-fuera de lo normal, como algo raro, algo extraño, porque, es lo que te digo, tuve que primero trabajarme yo misma la aceptación para darme cuenta ya que era algo normal. (Sofía)

Cuando como mujer te construyes al margen de lo que la mayoría considera 'normal', cuando no tienes una referencia de lo que te pasa, porque no ha sido presentado en tu entorno como una posibilidad más, el sentimiento no suele ser de armonía y estabilidad:

[...] yo creo que es como todo, como si eres de otra raza, de otra cultura, de otra religión, al final tú no apareces en ningún sitio, no te sientes identificado, no te ves reflejado y al final eso también hace que bueno, no sé si como tal no tengas menos derechos o se te puedan quitar, pero bueno, sí ahí ya sí partes de una base inferior. (Idoya)

En cualquier caso, se producen conflictos internos de gran calado, ya que hay una percepción de no estar en la línea de los deseos sexuales «normales». Puede surgir el autorrechazo, la culpa y la vergüenza por sentir así:

Y que el problema sigue siendo los tabúes mentales y sobre todo la homofobia interiorizada, que significa falta de visibilidad, que significa esconderse, que significa no naturalizar. O sea, el problema, yo creo gordo, que queda ahora que combatir es ese. (Herminia)

Continúa señalando que el autorrechazo es más agudo cuanto más reducido es el hábitat, por lo general más conservador:

[...] pero sí que paralelamente hay un montón de gente en las ciudades como esta, que viven en el oscurantismo más total, que se dan vergüenza a sí mismas. O sea, es una barbaridad. (Herminia)

Esta misma sensación la corrobora una mujer extranjera que reside en una pequeña ciudad española:

[...] las lesbianas no son visibles, porque muchas de ellas no sé si sienten vergüenza o si... Veo eso, pero también veo que es una ciudad pequeña, que aquí todo el mundo se conoce, que la gente tiene su familia aquí al lado. Entonces me llama mucho la atención ver mujeres de 50 o 60 años [...] que todavía utilice, por ejemplo, es que a mí el término 'pareja' [...] no me gusta.

Feminismo/s 33, junio 2019, pp. 297-322 


\section{M. ${ }^{a}$ Ángeles Goicoechea GaOnA, M. ${ }^{a}$ José Clavo Sebastián y \\ REMEDIOS ÁlVAREZ TERÁN}

Feminismo y derechos para las mujeres homosexuales

Yo digo: «Mi novia», porque es que cuando dicen: «Mi pareja», me siento como si tuviera 100 años y me cae una losa [...] Para mí es un eufemismo. (Uxue)

Y es que no es fácil liberarse de los estereotipos y aceptar una identidad sexual menospreciada por el entorno. Algunas nunca lo consiguen y viven clandestinamente la autenticidad de sus deseos, otras sí lo logran y viven en plenitud. Tanto en un caso como en el otro los procesos son complicados.

\section{6. ¿FEMINISTA O NO?}

Todas las informantes han mostrado su posicionamiento frente al feminismo, porque es una pregunta que se hizo explícitamente en todos los encuentros. Hay mucha pluralidad en sus aportaciones, y las que responden afirmativamente delimitan el tipo de feminismo con el que se consideran alineadas. Tan solo 11 participan activamente en colectivos.

El $87,8 \%$ de las entrevistadas se considera feminista, aunque no con la misma intensidad ni en el mismo tipo de feminismo, siendo el $25 \%$ de ellas no radical y el $8,3 \%$ transfeminista.

No se siente feminista el 9,7\% de la muestra, y lo justifican así:

- No creen que el sexo sea determinante para las personas:

Si yo valoro mucho a los hombres, no sé, que no es por... es que no creo que el sexo determine... yo veo una persona, no veo un hombre o una mujer, pues veo a esta persona que es así y ya está. (Tania)

Me gusta la igualdad, entiendo que somos iguales, pero también reconozco que no somos tan iguales. (Úrsula)

- Sienten rechazo frente a ciertos postulados, aunque están de acuerdo con el principio básico de la igualdad:

[...] en un colectivo de mujeres feministas, y yo las veo por la calle hablando de su coño o paseando al coño por la calle, como allí tienen como un monumento, así en procesión y lo sacan, y como a veces siento que los hombres son lo peor, ¿no? Eso choca mucho con mi creencia ¿vale? No, no, no admito eso y quizás me genera ese bloqueo para no seguir introduciéndome. (Berta) 
- No lo tienen claro, porque dicen una cosa y su contraria, lo que hace dudar de su verdadero posicionamiento:

[...] históricamente fue necesario. Pero creo que ha llegado un punto que se desvirtúa. O sea, a mí no me gustan las separaciones. No me gusta el feminismo de 'vamos a machacar... vamos a machacar a los tíos'. Que lo hay. (Gema)

En la literatura se explican estas actitudes hacia el feminismo, pues «formar parte de un grupo explotado no hace que una persona sea más propensa a oponer resistencia» (hooks 121).

Como no existe un pensamiento feminista único y excluyente, la forma de acercarse a la ideología es plural y depende de cómo lo concibe cada mujer. En un intento de clasificación, podemos encontrar las siguientes acepciones:

- Feminismo:

[...] simplemente que buscas la igualdad entre hombres y mujeres (Felisa).

Mucha gente cree que es igualdad, pero yo no pienso que sea igualdad. [E: ¿Y qué piensas?] O sea, yo creo que es la liberación de la mujer en todos los aspectos para, así como consecuencia, que se cree la igualdad. (Nerea)

Esta joven de 20 años nombra el término lesbofeminismo, pero reconoce que no sabe lo que es.

- Feminismos indefinidos, sin apellidos. Mercedes no tiene clara la diferencia entre los distintos feminismos, por eso responde que «en parte sí» se considera feminista:

Porque quiero la igualdad de todo, que es lo mismo un hombre que una mujer. Pero por otra parte hay unas feministas que van al extremo, que tampoco es eso. (Mercedes)

Sí, pero no de este feminismo de la diferencia. No reivindico ninguna clase de esencia ontológica de esta de un ser mujer, o ni siquiera un ser lesbiana para siempre, por siempre, esencial y tal. (Olivia)

No lo veo como antagónico tampoco al sistema patriarcal. Lo veo como algo más, como una forma de dar valor también -pues igual en la línea de lo que ibas antes- a los aspectos más femeninos, a las

Feminismo/s 33, junio 2019, pp. 297-322 
dimensiones más femeninas, que pueden estar en una mujer o en un hombre. (Ximena)

- Transfeminismo y teoría queer:

[...] la idea de romper con todo, no únicamente con el hombre o mujer, con los dos sujetos, sino con todo. Ahí la raza, la clase el... bueno, la estética de temas... tiene una apertura mayor, un discurso más amplio. Yo creo que abarca más los márgenes [...] va más allá, engloba más luchas y más social, más justo, más mundial. (Idoya)

En este sentido Gala también se situaría aquí, porque no está de acuerdo con concepciones del feminismo clásico:

Las feministas de la diferencia las veo muy biologicistas. Yo creo que si los hombres son muy diferentes a las mujeres en la sociedad de hoy, creo que no se debe a algo genético. Entonces claro, por eso no me gusta, porque sí que puedo decir: «Parece que somos de mundos diferentes». Pero no sé, es que por ejemplo con mi ex que es chica, tenía comportamientos tan socializados como masculinos, o sea, $\tan$... que digo pero a esta también le podría decir que somos de otro planeta. No lo sé. Entonces como creo que es educacional, no sé. (Gala)

En ocasiones aparece el desencanto tras el activismo más innovador:

[...] varias veces también hemos tratado el tema del armario y pensamos, que empezamos a teorizar mucho con la teoría queer, pero hemos vuelto un poco al esencialismo, porque vemos que todavía faltan un montón de cosas por avanzar [...] la no definición creo que nos vuelve a meter en el armario. (Idoya)

Entre las lesbianas militantes no hay contradicción en compartir feminismo y activismo LGTB. Como venimos mostrando, hay quienes consideran que el feminismo defiende los derechos de cualquier mujer por el hecho de serlo, por lo tanto, también los suyos:

Las mujeres lesbianas son mujeres y el feminismo ha sido importantísimo en el avance de los derechos de la mujer [...] Si ser lesbiana puede ser una cosa indisoluble de ser mujer, podríamos distanciarlo del feminismo, pero es que la lesbiana es una mujer. Entonces es que todos los avances en la mujer también es avance en la mujer lesbiana. (Herminia)

Feminismo/s 33, junio 2019, pp. 297-322 


\section{M. a Ángeles Goicoechea GaOna, M. ${ }^{a}$ José Clavo Sebastián y \\ REMEDIOS ÁlVAREZ TERÁN}

Feminismo y derechos para las mujeres homosexuales

Mientras que otras tienen en cuenta que el feminismo les ha permitido ser las mujeres empoderadas y valientes que son hoy, aunque también las está ignorando:

Yo creo que soy como soy gracias al feminismo. Y eso lo digo, o sea, si yo soy así, tengo este poder y poderío para salir del armario y hacer con mi vida [...] casi lo que me da la gana es gracias al feminismo. Sí, y sí que creo que el feminismo puede cambiar el mundo, porque el feminismo real sí que rompe contra las jerarquías, contra las clases, o sea, aparte de una ideología política, creo que es un estilo de vida. Y no sé, le debo mucho al feminismo [...]

Yo echo de menos, por ejemplo, en el feminismo -yo como feminista que soy- creo que el asunto lésbico es el asunto de las lesbianas. Y me parece un problema, porque creo que el feminismo tiene que ser inclusivo y todos tenemos que luchar por todos los derechos. (Josune)

Alguna de las entrevistadas feministas cree que hay un avance notable en la consecución de derechos y en la inclusión que ha llevado a cabo el feminismo:

Que hay muchos feminismos posibles, que todo el mundo entra, que se reconoce que las lesbianas hemos sido una parte fundamental del feminismo en España, incluso llegan las transexuales a ser aceptadas como mujeres feministas. Todo ese debate ya se va asentando, pero cuando yo empecé -a pesar de ser una parte importante del grupo- todavía no se nos reconocía especialmente, ¿sabes? Se hablaba de necesidades de mujeres hetero, pero estamos aquí y somos un empuje fundamental, porque yo creo que las lesbianas nos hemos dado cuenta por la doble discriminación, si quieres llamarlo así, mujeres y además homosexuales y de milagro no somos negras, porque ya lo tendríamos todo, que hacía falta esa lucha y esa igualdad de derechos con los hombres. (Leticia)

Otras, reconociendo la necesidad de visibilizarse cada día, consideran que hay que seguir reclamando un espacio para las mujeres lesbianas:

Pero sí me parece que el 8 de marzo hay que ser mujer, y el 28J desde luego, hay que ser lesbiana y que todavía hace falta, sí, sí, enarbolar esa bandera y ese discurso y decir: «Soy lesbiana y tal». No siento esa necesidad en todos los ámbitos de mi vida ni conmigo misma el cien por cien del tiempo en situarme desde ahí, pero desde luego hacia fuera y con nosotros, sí que me parece que todavía es un tiempo. (Olivia)

Finalmente, las más jóvenes perciben la diversidad de una forma más amplia, y dicen no necesitar un espacio propio:

Feminismo/s 33, junio 2019, pp. 297-322 


\section{M. a Ángeles Goicoechea GaOna, M. ${ }^{a}$ José Clavo Sebastián y \\ REMEDIOS ÁlVAREZ TERÁN}

Feminismo y derechos para las mujeres homosexuales

Aunque también saludo con alegría estas manifestaciones que decimos en la manifestación, estas diversidades y estos personajes y estas puestas en escenas, y estos lenguajes nuevos de montones de chicas, chicos y chiques, no tienen ya esa necesidad de esas etiquetas tan cerradas o buscan otras formas o se viven de otras maneras, ¿no? Me parece un paso para adelante. (Olivia)

Como vemos, la pluralidad en una muestra no muy numerosa es reseñable. Podemos decir que casi cada mujer tiene su forma de sentirse lesbiana.

\section{REIVINDICACIONES LESBIANAS}

Las reivindicaciones de las mujeres homosexuales se canalizan a través de los colectivos que trabajan por conseguir derechos. El feminismo y el activismo LGTB son los dos ejes fundamentales para sus luchas.

Sin embargo, una queja constante de las mujeres lesbianas es que han continuado siendo invisibles en ambos espacios. En el primer caso, porque el feminismo ha priorizado las demandas de todas las mujeres sobre las de las lesbianas, de forma que sus especificidades han sido siempre pospuestas:

Por eso igual en el feminismo, yo creo que las luchas con las bolleras o trans quedan a un lado, porque las demandas son otras. Las demandas son el aborto, las demandas son las agresiones machistas, qué pasa con otro tipo de agresiones [...] Por ejemplo, nosotras con el movimiento o con parte del movimiento feminista hemos tenido conflictos por eso y prácticamente en todos los años, porque a la hora de hacer los comunicados nuestros párrafos no se metían, porque no se iban a entender, en nuestro tema nunca se trabaja. Bueno nuestro tema, quiero decir el lesbianismo o la diversidad sexual nunca se trabaja. (Idoya)

Patricia cree que son dos luchas compatibles pero distintas:

Me ha ayudado a mis derechos como mujer. Pero como mujer lesbiana nunca lo he sentido así. O sea, yo he diferenciado siempre, no sé muy bien por qué, entre la lucha feminista y la lucha LGTB. [...] aunque muchas mujeres lesbianas estamos en movimiento feminista, es como una lucha por un concepto de mujer más general, donde quepamos todas. Pero cuando yo milito en LGTB, milito por cosas particulares que les pasa a las mujeres lesbianas o a los hombres. (Patricia)

En el segundo, porque las asociaciones mixtas de homosexuales, cuando están dirigidas por hombres, se olvidan de las reivindicaciones específicas 


\section{M. ${ }^{a}$ Ángeles Goicoechea GaOnA, M. ${ }^{a}$ José Clavo Sebastián y

Feminismo y derechos para las mujeres homosexuales

femeninas. Por ello, surgen grupos exclusivamente de mujeres, como ' 7 menos 20', en Vitoria, que se plantean una forma de trabajo horizontal. Este grupo -no constituido como asociación-pretende un lugar de encuentro para lesbianas en una ciudad donde no existen muchos espacios para ellas. Y dan un paso más hacia el empoderamiento y el desarrollo individual que sirve de base para poder trabajar en lo público:

Y, bueno, yo creo que el activismo une y sí. Y luego también pues para cada cual yo creo que nos ha venido muy bien para nuestro trabajo personal, al final leer, debatir, cuestionarte también te hace avanzar, pero no solamente en el lesbianismo sino yo creo en muchos factores a nivel social de qué mundo queremos y cómo nos gustaría que fuese. (Idoya)

Las reivindicaciones más constantes de las entrevistadas son:

- Igualdad en el uso del espacio público por parte de mujeres y hombres:

[...] poder ir a casa sola por la noche sin tener miedo a que te vaya a pasar algo. (Felisa)

- Igualdad en cuanto al uso de la palabra en lugares públicos:

[...] poder hablar y decir algo sin tener miedo a que por ser mujer no vayan a tomar tu opinión igual que por ser un hombre. (Felisa)

Esta dificultad que muchas mujeres expresan, tiene su origen en la educación no igualitaria recibida, y supone una falta de hábito y de empoderamiento. En el grupo 7 menos 20 se ejercita esta habilidad entre colectivos mixtos:

[...] y la relación que hemos tenido, nosotras ahí como tenemos claro cuál tiene que ser nuestra voz que tenemos que tener presencia y sino no nos interesa, a las demandas que hemos tenido de "Joe, no habláis o no tal». También pensamos que se tienen que cuestionar si dejan espacio para hablar, qué nos suponía a nosotras hablar y qué les supone a ellos, etcétera.

Entonces siempre que hemos tenido algún conflicto de estos también lo hemos expuesto y entonces hemos intentado trabajarlo desde ahí: es que el punto de partida no es el mismo. (Idoya) 
- Igualdad con respecto a las mujeres feministas heterosexuales:

[El conjunto de demandas] está en el mismo saco. Y eso las feministas heterosexuales no lo veían. Te miraban como: «Bueno, bueno, pero como lo otro es más importante». Y no, no, es que es igual de importante una cosa que la otra y hasta que no lo pongamos encima de la mesa como igual, pues no vamos a estar en la misma igualdad dentro del feminismo este blanco y heterosexual en que vivimos. (Josune)

- Igualdad respecto a las parejas heterosexuales, en el tratamiento legal de consideración de pareja a todos los efectos:

[...] yo quiero una modificación de la ley del matrimonio igualitario. Yo no entiendo -yo ya te digo que para mí casarme fue que yo estoy a favor del matrimonio, o sea, a favor del matrimonio si una persona se quiere casar y que se llame matrimonio, porque hubo también mucho debate para que no se llamara matrimonio y yo quería que se llamara matrimonio- pero no entiendo por qué tenemos que casarnos para poder tener hijos. (Rosa)

En el Registro Civil, lo mismo. [...] un hombre puede inscribir allí a un hijo y no le preguntan nada. (Rosa)

- Igualdad en el trato médico-legal de la reproducción asistida:

[...] con los mismos derechos y que no tuviera una pareja lesbiana ni gay que casarse para poder luego tener un hijo o porque para acceder a los tratamientos de fertilidad, hay que estar casada. Entonces eso a mí me parece que es una discriminación bastante grande, porque si una pareja de hecho heterosexual va a un tratamiento de fertilidad, todo ya es más cómodo porque nadie le pregunta nada. (Rosa)

- Espacios de mujeres donde poder expresarse y compartir las vivencias:

[...] me junto con grupos mixtos, porque hay alguna celebración, alguna ocasión y tal, y yo no me siento igual de relajada, igual de cómoda que cuando estoy solo con lesbianas, no hablo con la misma naturalidad [...] Pero no es igual que cuando me siento en una mesa con mujeres lesbianas, pues hablamos de otra manera. No es tanta la diferencia, lo sé, es sutil, pero te relajas un poco más. (Leticia)

[...] los espacios femeninos son muy importantes para las mujeres, o sea, es un espacio donde tengas que estar tú, donde puedas exponer tus cosas. Yo la verdad que eso sí lo necesito, necesito espacios femeninos, femeninos y feministas también. (Uxue)

Feminismo/s 33, junio 2019, pp. 297-322 
- Atención a personas LGTB procedentes de otros países:

[...] estamos viendo una crisis de los refugiados de la hostia y nadie se plantea que esos refugiados, esas refugiadas muchas sean lesbianas, transexuales, gais y estén sus derechos todavía más perdidos, no sé cómo decir la palabra. Entonces, no sé, hay mucho por hacer todavía. Y aquí también nos ha vendido un poco el rollo de que como que ya está todo bien, y si está ya todo bien no habría mujeres en el armario. (Josune)

- Atención a personas LGTB de otros países donde no están reconocidos los derechos humanos:

Y aparte hay muchos países que es que sigue siendo ilegal ser homosexual. Y te matan por ello [...] una mujer árabe dice que es lesbiana y es que va a pique [...] Y también habría que centrarse en los países que no tienen esa formación. (Nerea)

- Educación y formación para el alumnado, profesorado y familias para el reconocimiento de todas las realidades LGTB:

Nos hemos dado cuenta que muchos profesores quieren trabajarlo y no saben cómo, necesitan herramientas. Luego mediáticamente se han puesto de moda los niños trans. ¡Puff! que ahí creo que estamos volviendo al binarismo (Josune)

Los padres, porque en sí también son los que educan en... Es que, por ejemplo, [...] en algunos sitios hay escuelas para padres, pues estaría muy bien que los padres participaran [...] porque es que en sí los padres son los que les van a transmitir los conocimientos y las cosas y luego el estilo educativo también que tengan los padres, pues influye mucho. (Nerea)

- Atención médica adaptada a lesbianas, como información sanitaria sobre enfermedades de transmisión sexual:

[...] trabajaban las de Bilbao en lo del virus del papiloma humano, que entre lesbianas, también se puede contagiar y tal. Y esa información no te dan en sanidad. (Josune)

O el trato en las consultas de ginecología:

Yo he oído muchas reivindicaciones de lesbianas en el ginecólogo, y no solo en el trato, sino en otros detalles. De un poco de cuidado

Feminismo/s 33, junio 2019, pp. 297-322 
con cómo me tratas, que yo no practico de todo, entonces mi cuerpo no está igual, ¿vale?. (Leticia)

\section{- Aceptación social:}

[...] intentar dar visibilidad sobre todo y que vean que no somos un bicho raro, que es que es algo normal, que es que pasaba en la época de mis abuelos, tatarabuelos, pasa ahora y va a seguir pasando. Le pese a quien le pese. (Nerea)

- Erradicar el machismo que afecta de forma particular a las lesbianas:

[...] que nos consideren como objetos sexuales de placer para un chico, sobre todo en el porno muchos chicos lo que más buscan son videos de lesbianas $[. .$.$] en el que te vean más como un objeto$ sexual que una persona. (Nerea)

- Evitar que las niñas y niños de familias homoparentales sufran 'homofamilia' o

la discriminación de los más vulnerables que son nuestros hijos y nuestras hijas [...] sufren este peso de la homofobia transformada en homofamilifobia por pertenecer, por nacer en el seno de una familia que tiene dos mamás o dos papás, o un papá o una mamá y/o lesbiana. (Patricia)

Voy a luchar por mis derechos y mis derechos a mi hijo bien». Es decir, porque mi hijo no es LGTB, no sé si será o no, pero que no tiene por qué ser LGTB, pero por lo menos yo lucharé, porque su familia sí que tenga los derechos que se merece. (Rosa)

Son muchas las reivindicaciones del colectivo, algunas soluciones son de índole legal, otras solo dependen de la actitud de las personas con las que interactúan. Los cambios de mentalidad son lentos, pero siempre son el resultado de la suma de voluntades individuales, de nuestras voluntades.

\section{CONCLUSIONES}

Las mujeres homosexuales constituyen un colectivo con problemas de reconocimiento social porque, por su orientación sexual, transgreden las normas heterosexuales. La sociedad patriarcal utiliza en mayor o menor medida 
procedimientos simbólicos y normativos para discriminarlas. Estos mecanismos de poder tienen consecuencias en sus vidas ya que, por un lado, generan rechazo social hacia ellas a través de estereotipos negativos, y, por otro, desempeñan un papel en la construcción de sus identidades promoviendo en muchos casos homofobia interna y, en casi todos, problemas importantes de autoestima y aceptación.

Estas cuestiones se manifiestan en la autodenominación que las entrevistadas hacen sobre su orientación afectiva y sexual, que en algunos casos llega al rechazo de cualquiera de los términos que da nombre a su homosexualidad.

Las mujeres lesbianas sienten la necesidad de luchar por sus derechos. Históricamente sus reivindicaciones se han canalizado desde el feminismo y los movimientos de defensa de las minorías sexuales (Trujillo 21). Al inicio del periodo estudiado, el marco feminista acoge sus reivindicaciones con todas sus complejidades y contradicciones. Iniciado el siglo XXI, las asociaciones LGTB, que incluyen a los hombres gais y a otras personas diversas sexual y afectivamente, lanzan un mensaje mucho más nítido, específico y amplificado, con mayor calado social y, sobre todo, obtienen resultados en forma de leyes que afectan a todo el colectivo, la ley del matrimonio igualitario es un claro ejemplo.

La mayoría de las entrevistadas se declara feminista en distintos grados, es decir, está a favor de sus reivindicaciones y todas ellas reconocen que sus logros también les afectan.

Por otro lado, aquellas que militan en colectivos LGTB y/o feministas, opinan que es más lo que las lesbianas han aportado al feminismo que el apoyo de las militantes heterosexuales a sus reivindicaciones específicas. Por este motivo, este texto recoge un apartado concreto de requerimientos de las lesbianas que den respuesta a sus necesidades particulares.

\section{BIBLIOGRAFÍA}

Anzaldúa, Gloria. Borderlands/La Frontera: The New Mestiza. San Francisco: Aunt Lute Books, 2007.

Centro de Investigaciones Sociológicas. Actitudes de la Juventud ante la diversidad sexual. Estudio n. ${ }^{\circ}$ 2854, noviembre-diciembre de 2010. Madrid: CIS, 2011. Fraser, Nancy, y Axel Honneth. ¿Redistribución o reconocimiento? Madrid: Morata, 2006. 


\section{M. ${ }^{a}$ Ángeles Goicoechea GaOnA, M. ${ }^{a}$ José Clavo Sebastián y \\ REMEDIOS ÁlVAREZ TERÁN}

Feminismo y derechos para las mujeres homosexuales

Gimeno, Beatriz. Historia y análisis político del lesbianismo. Barcelona: Gedisa, 2007.

Goicoechea Gaona, María Ángeles, Olaya Fernández Guerrero, María José Clavo Sebastián, y Remedios Álvarez Terán. Chicas que entienden. In-visibilidad lesbiana. Barcelona-Madrid: Egales, 2015.

hooks, bell. El feminismo es para todo el mundo. Madrid: Traficantes de Sueños, 2017.

Osborne, Raquel. «Entre el rosa y el violeta. Lesbianismo, feminismo y movimiento gay: relato de unos amores difíciles». Lesbianas. Discursos y representaciones. Coord. Raquel Platero. Barcelona: Melusina, 2008. 85-106.

Pineda, Empar, «Mi pequeña historia sobre el lesbianismo organizado en el movimiento feminista de nuestro país». Lesbianas, discursos y representaciones. Coord. Raquel Platero. Barcelona: Melusina, 2008. 31-60.

Platero, Raquel, y Cristina Fernández Laso. «Conceptos clave sobre homosexualidad y lesbianismo». <https://studylib.es/doc/6593858/ conceptos-clave-sobre-homosexualidad-y-lesbianismo>

Rich, Adrienne. "Compulsory Heterosexuality and Lesbian Existence». Signs: Journal of Women in Culture and Society 5 (1980): 631-660.

Rubin, Gayle. «Tráfico de mujeres: notas sobre la 'economía política' del sexo». Revista Nueva Antropología. VIII. 030 (1996): 95-145.

Sau, Victoria. Mujeres lesbianas. Barcelona: Zero-Zyx, 1979.

Trujillo Barbadillo, Gracia. Deseo y resistencia: treinta años de movilización lesbiana en el Estado español (1977-2007). Barcelona-Madrid: Egales, 2009.

Villar Sáenz, Amparo, e Inmaculada Mujika Flores. «Lesbianas: derecho de asilo para mujeres perseguidas por orientación sexual». Bilbao: Centro de Estudios y Documentación Aldarte. <http://www.aldarte.org/comun/imagenes/documentos/informeLESBIANASDERECHODEASILO.pdf>

Villar Sáenz, Amparo. ¿Lesbiana? Encantada, es un placer. Bilbao: Centro de Estudios y Documentación ALDARTE, Universidad del País Vasco, 2005.

Feminismo/s 33, junio 2019, pp. 297-322 